\title{
Evaluation of the Simultaneous Effects of Sulfate Reducing Bacteria, Soil Type and Moisture Content on Corrosion Behavior of Buried Carbon Steel API 5L X65
}

\author{
Fazlollah Madani Sani ${ }^{1,2, ~ *, ~ A b d o l l a h ~ A f s h a r ~}{ }^{2}$, Maryam Mohammadi ${ }^{2,3}$ \\ ${ }^{1}$ Department of Chemical and Biomolecular Engineering, Institute for Corrosion and Multiphase \\ Technology, Ohio University, Athens, OH 45701, USA \\ ${ }^{2}$ Department of Materials Science and Engineering, Sharif university of Technology, P.O. Box 11365- \\ 9466, Tehran, Iran \\ ${ }^{3}$ Department of Materials engineering, Vancouver Campus, Frank Forward Building, 309-6350 Stores \\ Road, Vancouver, BC Canada V6T 1Z4 \\ *E-mail: fm874012@ ohio.edu, fazlollah.madani.sani@gmail.com
}

doi: $10.20964 / 110294$

Received: 16 December 2015 / Accepted: 13 February 2016 / Published: 1 April 2016

For the first time, the simultaneous effects of sulfate reducing bacteria (SRB), soil type and moisture content on corrosion behavior of a pipeline steel were investigated. Corrosion weight loss measurements were performed in abiotic control and SRB-active conditions, at three different moisture contents, and in two types of soils. Results showed that the presence of SRB in the soils, although increased the corrosion rate and aggravated pitting corrosion at low moisture contents, had a protective effect at high moisture contents. The corrosion rates showed a maximum at the saturation moisture content (SMC) of the soils. Soil physicochemical analyses showed that the corrosion rate and soil resistivity were not related while texture and chemical content of the soils had strong effects on the corrosion rate. At low moisture contents, two layers of corrosion products formed on the surface of the coupons in both soils. X-ray diffraction (XRD) results showed that the outer layer was ferric oxyhydroxides in both abiotic and SRB-active conditions. The inner layer was magnetite in the abiotic condition and a mixture of magnetite and iron sulfides in the SRB-active condition. At high moisture contents, one layer of corrosion products formed on the surface in both soils, which was green rusts (GR) in the abiotic condition and a mixture of GRs and iron sulfides in the SRB-active condition.

Keywords: Carbon steel; Sulfate reducing bacteria; Soil corrosion; Moisture content; X-ray diffraction FULL TEXT

C 2016 The Authors. Published by ESG (www.electrochemsci.org). This article is an open access article distributed under the terms and conditions of the Creative Commons Attribution license (http://creativecommons.org/licenses/by/4.0/). 